\title{
A INTERFACE ENTRE CULTURA LITERÁRIA E HISTÓRIA NO NÚCLEO DE PESQUISA EM LITERATURA DIGITALIZADA-NUPLID
}

\author{
Olívia Candeia Lima Rocha* \\ Saulo da Cunha de Serpa Brandão*
}

\begin{abstract}
RESUMO: Os periódicos são fontes perecíveis, sujeitas ao dilaceramento, à umidade e ao fogo. Os periódicos são documentos que trazem as marcas de sua época, seus discursos, embates políticos, valores, contradições sociais e econômicas e registram também informações sobre a cultura. Esse texto discute resultados do projeto de pesquisa, Resgate de uma História Feminina No Piauí:Mulheres Escritoras. A pesquisa documental foi realizada no Arquivo Público do Piauí em periódicos publicados em Teresina no período de 1875-1925. Foram utilizados recursos como máquina fotográfica digital e programas como o Corel Draw. Os textos foram digitalizados e disponibilizados no sítio do Núcleo de Pesquisa em Literatura Digitalizada-NUPLID. Verificou-se que a maioria dos textos publicados e selecionados remetia a uma autoria feminina, mas que as mulheres começavam a participar dos espaços de publicação, utilizando estratégias como o uso de pseudônimos. Além disso, foram digitalizados diversos textos publicados por literatos do período, dentre os quais, Celso Pinheiro e Lucídio Freitas, nomes que figuram entre os fundadores da Academia Piauiense de Letras em 1917. Observa-se que além do caráter noticioso, os jornais divulgavam a produção literária dos autores piauienses do período.
\end{abstract}

PALAVRAS-CHAVE: História. Memória. Literatura. Periódicos. Mulheres.

\section{Introdução}

Os periódicos constituem-se como fontes perecíveis, suportes de notícias passadas, parecem de pouca importância no dia seguinte, mas com o passar do tempo, tornam-se preciosidades e acentuam seu caráter de fonte histórica e lugar de memória. Os jornais além da função noticiosa exerciam também o papel de entretenimento, publicando folhetins, contos e poesias. É o que se verifica, em relação aos periódicos publicados entre 1875 e 1925 que compõem o acervo do Arquivo Público do Piauí.

Universidade Federal do Piauí - Campus Senador Helvídio Nunes de Barros. Imeio: candeia09@hotmail.com.

"Universidade Federal do Piauí. Imeio: saulo@ufpi.edu.br.

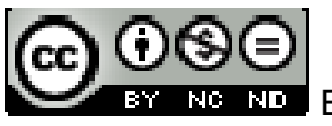

Texto Digital, Florianópolis, v. 8, n. 2, p. 102-113, jul./dez. 2012. ISSNe: 1807-9288 
Os jornais constituíram-se como fontes de consulta para a realização da pesquisa no Projeto Mulheres Escritoras, que buscou catalogar textos relacionados a mulheres e produções de autoria feminina expressa ou com pseudônimos. Dentre os periódicos consultados, menciona-se, os jornais, Piauí (1902), O Piauí (1917, 1921, 1925, 1926), O Semanário (1878 a 1880), Diário do Piauí (1912) e $A$ Imprensa $(1925,1926)$ e as revistas, Alvorada (1909-1911), Litericultura (1912) e O automóvel (1929).

Os textos foram fotografados com máquina digital, trabalhados em programas gráficos como o Corel Draw e disponibilizados para o conhecimento da sociedade e o estudo da comunidade acadêmica através do sítio do Núcleo em Literatura Digitalizada - NUPLID (http://www.ufpi.br/huplid/). Esta pesquisa recebeu apoio da FAPEPI - Fundação de Amparo à Pesquisa do Estado do Piauí e do Conselho Nacional de Desenvolvimento Científico e Tecnológico-CNPq, através da concessão de bolsas a estudantes de graduação da UFPI e colaboradores técnicos.

\section{A tecnologia com suporte da memória}

A memória é seletiva, constitui-se de atos que envolvem esquecimentos e lembranças. E dessa forma, engendram atos de intencionalidade, de construção de silêncios e suportes de memória. O desenvolvimento tecnológico do século XX tem sido profícuo em mecanismos de produção de documentos sonoros e imagéticos, que podem se constituir em fontes de pesquisa (NORA, 1993; POLLAK, 1989).

O registro de sinais gráficos em suportes de pedra e papiros produzidos a partir de fibras vegetais indica a necessidade do homem de legar para a posteridade, suas narrativas históricas, produções filosóficas, jurídicas, administrativas e literárias. A produção desses registros faz com que na antiguidade, as sociedades 
também se preocupem em criar locais que funcionem como arquivos e bibliotecas.

No século XVI, o advento da prensa permitiu a difusão de materiais que possibilitaram a circulação da palavra escrita, dinamizando a divulgação dos acontecimentos, marcando o surgimento da imprensa, com a publicação de periódicos e livros. Inaugurando uma nova fase na história da humanidade, na qual, começou a ser suplantada uma época em que o conhecimento e as fontes escritas eram de acesso restrito a uma elite letrada, geralmente clérigos e monges e confinadas no interior de mosteiros. Pode-se dizer que, a época moderna inaugura o surgimento de uma era em que informação e conhecimento passam a ser valorizadas. (EISENSTEIN, 1998)

Entretanto, o papel utilizado como suporte para periódicos e livros, constitui-se em uma fonte perecível, sujeita ao dilaceramento, à umidade, a oxidação, a ação de insetos e ao risco de incêndios. A ausência de políticas de digitalização, e mesmo de infraestrutura adequada, fazem com que muitos arquivos tornem-se depósitos de documentos, que embora pese um esforço de memória, a mesma encontra-se constantemente ameaçada pelo desaparecimento de seus suportes materiais.

A tecnologia pode constituir-se em um instrumento para digitalização de textos que de outra forma estariam relegados ao esquecimento e ao desparecimento, servindo como suporte da memória social e literária, e sendo usados na produção de acervos de pesquisa.

Os textos foram digitalizadas, com o uso de uma máquina fotográfica digital, juntamente com a anotação das referências de autoria, título do texto, periódico, local e data de publicação em cada fotografia. As imagens foram transferidas e armazenadas no programa Image Transfer. Após esse procedimento eram identificadas com o nome ou pseudônimos das autoras ou autores, e quando não assinados, considerou-se o título. 
O "Corel Draw" foi o programa utilizado para a formatação das imagens. Para esse processo padronizou-se um modelo. Que inclui o corpo textual e apresentação das referências bibliográficas. As imagens são exibidas em JPEG, o que proporciona economia de espaço, e maior agilidade, sem prejudicar a nitidez. As mesmas após serem tratadas foram arquivadas nas pastas; escritoras, escritores, sobre mulheres e pseudônimos. No site, essas são as opções de acesso aos textos. Na opção "sobre mulheres" estão textos de autoria feminina e masculina que discutem o cotidiano feminino na sociedade e os papéis atribuídos ao sexo feminino.

Devido às condições de perecibilidade e ameaça de lacração dos periódicos no Arquivo Público do Piauí, também foram digitalizadas diversas poesias e contos de autores com representativa atuação literária na época, alguns dos quais participaram da fundação da Academia Piauiense de Letras em 1917, como Lucídio Freitas e Celso Pinheiro.

\section{As mulheres e a escrita}

A produção historiográfica, não é um ato neutro, desinteressado, mas sim recoberto de intencionalidade que recobre as opções do historiador na escolha dos temas de pesquisa, aportes teóricos e metodológicos, e seleções de informações para produzir as narrativas historiográficas (FERRO,1989).

O domínio masculino sobre a produção escrita colaborou para a produção de narrativas históricas que partiam de seus lugares sociais. Assim, os homens elegeram como temas importantes para serem abordados, a atuação masculina no espaço público, na política, na guerra, na produção cultural e do conhecimento.

Entretanto, a cultura letrada começou a inserir as mulheres em suas veredas. Para Hobsbawm (1988), o surgimento de uma nova mulher deve-se à necessidade das classes abastardas de distinguirem-se socialmente. Além disso, 
emergem novos valores e modelos, dentre os quais, a reformulação dos modelos femininos na família, na qual, agregando uma melhor preparação cultural, incluindo conhecimentos literários e musicais. A mulher, além de personagem de obras literárias torna-se também leitora de romances e folhetins. Os folhetins eram publicados em jornais, como entretenimento, assemelhando-se às novelas, na qual se acompanha com curiosidade, o desenrolar da história na medida da publicação dos capítulos. O sucesso de um folhetim fomentava o mercado literário, e poderia ser editado em livro (TELLES, 2000; BUITTONI, 1986).

No século XIX, registram-se as primeiras iniciativas em torno da educação feminina e o surgimento de uma significativa rede de mulheres que lançavam periódicos e publicavam romances questionando os lugares femininos na sociedade brasileira e abordando temas polêmicos, como, abolição da escravatura, proclamação da república. Dentre as questões femininas, destacamse temas como educação e restrições que cerceavam as possibilidades femininas na sociedade, em relação ao trabalho e à escolha do marido, por exemplo.

Verificou-se nos jornais e revistas consultados, a presença de esmagadora superioridade numérica de textos de autoria masculina, em relação aos textos assinados por mulheres ou por pseudônimos que remeteriam a uma autoria feminina. Esse fato demonstra que, no Piauí, a literatura e a imprensa eram áreas de domínio masculino nos quais a mulher iniciava a enveredar. Deve-se considerar alguns aspectos relacionados a essa disparidade entre a produção masculina e a feminina.

A principal perspectiva para a vida das mulheres era o casamento, de forma que a educação feminina do período em questão baseava-se em conhecimentos rudimentares de escrita, matemática, trabalhos manuais, e no início do século XX, incluiu-se a música, como fator de refinamento cultural para as mulheres das famílias ricas. A maior parte das mulheres da época, não tinha acesso à educação, eram poucas as escolas públicas, as meninas das famílias pobres necessitando complementar a renda familiar empregavam-se como domésticas e 
na Fábrica de Fiação. As famílias de melhor situação financeiras começaram a investir na educação feminina no início do século $X X$, visando preparar as mulheres para o melhor desempenho dos papéis de mão e esposa, pois ocupado dos cuidados domésticos cabia À mulher formar os futuros cidadãos de uma sociedade que principiava a associar educação a progresso. (CASTELO BRANCO, 1998).

Mesmo as mulheres alfabetizadas e provenientes de famílias abastadas não exerciam a direção de jornais, restando-Ihes participar como colaboradoras de jornais e revistas como a Alvorada (1909-1911). No período estudado apenas o jornal Borboleta (1904-1906) contava com uma direção exclusivamente feminina, sendo redigido por Alaíde Bulamarque, Anthonieta Bulamarque e Maria Bulamarque e Maria Amélia Rubim.

Os pseudônimos constituíram-se como um recurso fundamental para a prática escriturística de muitas mulheres, entre as piauienses podemos citar Amélia Bevilaqua, que começou a publicar em 1898, na Revista do Brasil, assinando com as iniciais "AB". (MENDES, 2003). Ainda, que mesmo escrevendo sob pseudônimo, as mulheres precisavam passar pelo crivo dos diretores de redação dos jornais e contar com sua colaboração, como, as mulheres que publicavam no jornal O Piauhy em meados da década de 1920, e tinham como condição que Íris um dos redatores do jornal conhecesse suas identidades.

O espaço literário constituía-se em um espaço sociocultural em processo de conquista pelas mulheres piauienses da época, em que estavam em jogo relações de força e poder, o que tornava necessário o estabelecimento de ações, como a organização do periódico Borboleta ${ }_{1}$ e o uso de pseudônimos. Luiza Amélia de Queiroz, testemunha em seu poema "A Mulher" sobre a interdição que se lançava à escrita feminina, pois se considerava que ao buscar ocupar um espaço que não the era tradicionalmente reservado, transgredia as leis estabelecidas para o sexo feminino na época (NUNES, 1875). Nessa perspectiva, o uso de pseudônimo para ocultar a identidade feminina constituía-se em um 
recurso fundamental para proteger as mulheres das críticas dos paladinos da moral (MAGALHÃES, 1998; MORAIS, 2002).

No último quartel do século XIX, o uso de pseudônimos e assinaturas sobre iniciais já era muito significativo. Pseudônimos, como "O Bandarra", "Podinho", "Um Pobre Homem", entre outros, remetem a uma autoria masculina. Esse recurso foi utilizado pelos homens, para fazer críticas políticas e para tecer comentários desaprovando a conduta feminina para se posicionarem desfavoráveis à ampliação do papel social da mulher (ROCHA, 2002). Pode-se depreender que os homens também usavam pseudônimos para procurar evitar as perseguições políticas, tendo em vista que Segundo Queiroz (1998), a política da época era marcada por ameaças, espancamentos, assassinatos, empastelamento e incêndio de jornais, o que forçava até mesmo a busca de exílio em outros estados pelos intelectuais.

O Semanário (1878 a 1880), no momento da pesquisa era o único periódico do último quartel do século XIX, disponível para consulta no Arquivo Público. Neste também foram encontrados textos assinados por "A Valenciana", "Maria Del Pilar" e "Tumira". "Tumira" pode ser um pseudônimo que oculte a identidade de uma mulher. Não deixa de ser intrigante que suas poesias tenham por título, No Jardim", e "Flores Incultas", sendo que esse é o título do primeiro livro de Luiza Amélia de Queiroz, publicado em 1875.

Segundo Freitas (1998), Luísa Amélia publicou várias poesias avulsas em jornais, mas não informa se a autora fez uso de pseudônimo. Pinheiro Filho (1997) informa que, Luísa Amélia colaborou com o jornal Telefone (1883-1889), contudo não foi possível consultar este periódico, devido o mesmo encontrar-se lacrado no Arquivo Público.

São recorrentes durante 0 período pesquisado, textos que expressavam "mandamentos" a serem seguidos pelas mulheres, visando assim, ditar normas para a conduta feminina, especialmente no que se refere ao casamento. O início 
do século $X X$ foi um período de efervescência cultural em que o cinema ê revistas propagavam novas tendências de moda e comportamento.

Nesse período Igreja e Maçonaria se defrontaram em diversos aspectos, entre eles, a educação feminina. A Maçonaria afirmava desejar a mulher liberta dos "ensinamentos obscuros" e a Igreja a queria afastada de leituras e comportamentos considerados nocivos, entretanto as duas perspectivas reforçavam a perspectiva dos papéis de mães e esposas para as mulheres (CASTELO BRANCO, 1998; PINHEIRO, 2001).

Nas primeiras décadas do século XX, o cinema e as revistas apresentam novos modelos de comportamento social, esses aspectos juntamente com o movimento feminista contribuíram para que o papel social da mulher passasse a ser tema de debates e polêmicas. A fissura provocada por esses debates foi acompanhada pela elaboração de novos discursos sobre procedimento feminino diante do amor, como, demonstram os textos, Mal Sem Cura assinado por "Jacques Constant", e A mulher de Buridan, assinado por "Camile Mauclair", encontrados no jornal Diário do Piauí (1912). Esses textos têm protagonistas femininas e permeiam questões que confrontam amor e razão. Em "Mal Sem Cura", Fernanda apaixona-se pelo médico e finge continuar doente. Ao ser levada novamente para a mesa de cirurgia, falece. Em suma, morre por amor. No texto "A mulher de Buridan", a protagonista desiludida com seu primeiro casamento, decide não se deixar apaixonar e escolher seu segundo marido de forma que a amizade e a conveniência the proporcionassem uma boa posição social. Ela tinha dois pretendentes, os quais recebia em sua casa para estudá-los, sem que eles soubessem um do outro. "Jacques Constant" aborda em seu texto um perfil feminino em que se deixar levar pela emoção leva a destruição, típico do romantismo, morrer de amor. "Camile Mauclair" por sua vez, apresenta uma protagonista que quer tomar seu destino nas mãos, quer escolher com a voz da razão, desafia a moral, aceitando ser cortejada por dois homens e triunfa por meio da artimanha, fazendo com que o mais jovem, pensando tê-la conquistado, revele seu verdadeiro caráter. (CONSTANT, 1912; MAUCLAIR, 1912) 
Os textos de "Jacques Constant" e "Camile Mauclair" convergem no aspecto de que se deixar levar pela emoção é caminho de sofrimento e destruição. A razão é proclamada, em contraste com seu avesso, como ideal a ser alcançado. As primeiras décadas do século XX são marcadas também pela chegada de notícias sobre o movimento feminista, bem como, de publicações feministas. Esse contexto de polêmica e debate sobre os papéis sociais das mulheres evidencia-se em textos que discutem e o casamento, o voto feminino, a necessidade de instrução para as mulheres, assinados por pseudônimos como, "Acácia", "Berenice", "Bonina", "Eglantine" e "Violeta".

Paralelamente a nossa pesquisa, oportunamente digitalizou-se uma significativa parcela da produção poética masculina, principalmente no jornal Diario do Piauí (1912), o que resultou em vasto material, de atuantes escritores do período e fundadores da Academia Piauiense de Letras, como, Lucídio Freitas, Celso Pinheiro e Jonathas Batista, apenas para citar alguns.

\section{Conclusão}

O trabalho tem o mérito incontestável de evitar que informações contidas no material digitalizado se percam devido à destruição das fontes hemerográficas pela ação do tempo e outras ameaças ao papel, ou que ficassem indisponíveis aos pesquisadores pela ausência de uma política de digitalização e microfilmagem no Arquivo Público do Piauí.

A intersecção entre literatura, história, e tecnologias é um campo profícuo, e em se tratando de Piauí, pode-se dizer que estão sendo abertas veredas que propiciam abordagens interdisciplinares e fontes de consulta e trabalho a pesquisadores de diversas áreas, e numa dimensão espaço-temporal bastante ampla, tanto no sentido de posteridade, como flexibilidade em relação ao local de acesso às fontes. Além de diminuir o contato do pesquisador com a poeira, 
ácaros e bactérias que podem estar presentes em documentos antigos, especialmente em arquivos com políticas de preservação precárias.

Os textos digitalizados constituem-se em excelente material para enveredar pesquisas pertinentes à sociedade da época, seus conflitos com modernização e a mudança de costumes, entre outros. Dessa forma, acredita-se que ao disponibilizar esse material na rede mundial de computadores no site do NUPLID, contribui-se para estimular e facilitar pesquisas nas áreas de literatura, história e memória. O desenvolvimento tecnológico propicia a proliferação de suportes para textos e imagens. Mas também a socialização de informações em uma dimensão e velocidade inéditas

\title{
THE INTERFACE BETWEEN LITERARY CULTURE AND HISTORY IN THE NÚCLEO DE LITERATURA DIGITALIZADA-NUPLID
}

\begin{abstract}
The journals are perishable sources, subject to tearing, moisture and fire. The journals are documents that bear the marks of their time, their speeches, political clashes, values, social and economic contradictions and also record information about the culture. This paper discusses the results of a research project, Rescue of a Women's History In Piaui: Women Writers. The documentary research was conducted in the Public Archives of Piauí in Teresina published in journals in the period 1875-1925. We used features like digital camera and programs like Corel Draw. The texts have been digitized and made available on the website of the Núcleo de Pesquisa em Literatura Digitalizada-NUPLID. It was found that most of the documents selected referred to a female authorship, but that women began to participate in spaces for publication, using strategies such as the use of pseudonyms. In addition, we scanned many texts published by writers of the period, among them, Celso Pinheiro and Lucidio Freitas, names that are among the founders of the Piauiense Academy of Arts in 1917. It was observed that besides the news, newspapers spread the literary production of period.
\end{abstract}

KEYWORDS: History. Memory. Literature. Periodicals. Women.

\section{Referências}

BUITONI, Dulcília Schroeder. Imprensa feminina. São Paulo: Ática, 1986.

CASTELO BRANCO, Pedro Vilarinho. Mulheres plurais. Teresina: FCMC, 1998.

CONSTANT, Jacqes. Mal sem Cura. In: Diário do Piauí. Teresina: 01 de out. 1912, p. 1. 
EISENSTEIN, Elizabeth L. A revolução da cultura impressa: os primórdios da Europa Moderna. São Paulo: Ática, 1998.

FERRO, Marc. A História vigiada. Coleção O homem e a História. São Paulo: Martins Fontes, 1989.

FREITAS, Clodoaldo. Vultos piauienses: apontamentos biográficos. $2^{\mathrm{a}}$ ed. Teresina: FCMC, 1998.

HOBSBAWM, Eric. A era dos impérios (1875-1914). Rio de Janeiro: Paz e Terra, 1988.

MAGALHÃES, Maria do Socorro Rios. Literatura piauiense: horizontes de leitura e crítica literária (1900-1930). Teresina: FCMC, 1998.

MORAIS, Maria Arisnete Câmara de. Leituras de mulheres no século XIX. Belo Horizonte: Autêntica, 2002.

MAUCLAIR, Camile. A mulher de Buridan. In: Diário do Piauhy. Teresina: 17 set. 1912. p. 1-2.

MENDES, Algemira Macedo. Amélia Bevilaqua: Uma voz feminina piauiense no seu tempo. In: SANTOS, Francisco Venceslau dos. (Ogr.). Primas 4, geografias literárias- confrontos: o local e o nacional. n. 4. Rio de Janeiro: 2003. p. 134155.

NORA, Pierre. Entre memória e história. A problemática dos lugares. In: Projeto História, n. 10. São Paulo: 1993. p. 7-28.

NUNES, Luiza Amélia de Queiroz. Flores incultas. Parnaíba: [s.n], 1875.

PINHEIRO, Áurea Paz. As tensões entre clericais e anticlericais no Piauí, nas duas primeiras décadas do século XX. Teresina: FCMC, 2001.

PINHEIRO FILHO, Celso. História da imprensa no Piauí. $3^{\text {a }}$ ed. Teresina: Zodíaco, 1997.

POLLAK, Michael. Memória, esquecimento, silêncio. In: Estudos Históricos, vol. 2, n. 3. Rio de Janeiro: 1989. p. 3 - 15.

QUEIROZ, Teresinha. Os literatos e a República: Clodoaldo Freitas e Higino Cunha e as tiranias do tempo. $2^{\circ}$ ed. Teresina; João Pessoa: EDUFPI; UFPB, 1998.

TELLES, Norma. Escritores, escritos, escrituras. In: DEL PRIORE, Mary (org.). História das mulheres no Brasil. $3^{\underline{a}}$ ed. São Paulo: Contexto, 2000. p. 401 - 442. 
ROCHA, Olívia Candeia Lima. Uma perspectiva da inserção literária da mulher piauiense entre 1875 e 1950. In: Cadernos de Teresina, n. 33. Teresina: 2002. p. 4-17.

Texto recebido em 05/11/2012. 